\title{
Born in the USA: Exceptionalism in Maternity Care Organisation Among High- Income Countries
}

\author{
by Edwin van Teijlingen, Sirpa Wrede, Cecilia Benoit, Jane Sandall and Raymond DeVries \\ University of Aberdeen \& Bournemouth University; University of Helsinki (Finland); University of \\ Victoria (Canada); King's College London; University of Michigan (USA)
}

Sociological Research Online, Volume 14, Issue 1, < http://www. socresonline.org.uk/14/1/5.htm/>

doi:10.5153/sro. 1860

Received: 18 Aug 2008 Accepted: 27 Jan 2009 Published: 31 Jan 2009

\begin{abstract}
In lay terms, childbirth is regarded as a purely biological event: what is more natural than birth and death? On the other hand, social scientists have long understood that 'natural' events are socially structured. In the case of birth, sociologists have examined the social and cultural shaping of its timing, outcome, and the organization of care throughout the perinatal period. Continuing in this tradition, we examine the peculiar social design of birth in the United States of America, contrasting this design with the ways birth is organised in Europe. We begin by showing how several key characteristics of the US health care system including its inherent social inequality, its high level of medicalisation, and the substantial influence of private medical practice and insurance companies - influence the organization of maternity care there. We then explore how cultural characteristics of American society - its emphasis on individuality, the influence of moral conservatism in US politics, and the ease with which ordinary people take court action (the socalled 'litigation culture') - shape the delivery of care at birth. We conclude with a consideration of the implications of US maternity care exceptionalism for comparative sociological analysis.
\end{abstract}

\section{Keywords: Pregnancy, Comparative Studies, Exceptionalism, United States, Midwifery, Maternity Care, Birth}

\section{Introduction}

1.1 The social, cultural, and organisational practices surrounding childbearing in high and middle-income countries separate this normal life event from the everyday life worlds of women and their families. Labour and birth no longer take place at home in the presence of family; the "proper" way of birth now requires a visit to the hospital and the surveillance of medical staff. This is especially true in the US where the health system, the legal system, the media, and most of the population believe birth to be one of the riskiest events in a woman's life. Despite this hegemonic understanding of birth as risky, perhaps nowhere in the high-income world is there as much diversity in childbirth outcomes, and in the social circumstances of birth as in the US (Nelson \& Popenoe 2001; Sakala and Corry 2008).

1.2 The distinctive history of the US has given rise to the peculiar American way of thinking about birth and the organization of maternity care there. The US is a society that celebrates the heroic and favours aggressive approaches to its problems: values linked to its frontier past, where aggressiveness and bravery were necessary for survival (DeVries et al. 2004, 229). Dutton (2007) sees the American private-insurance approach to health care originating in the tensions between the core values of liberty and equality that form the foundation of the country's political culture. Within maternity care the relative absence of governmental involvement - part of this emphasis on liberty - has given rise to a business model of birth that favours active management techniques that turn childbirth into an intensive care situation (Perkins 2004). Similarly, Davis-Floyd (1987) argues that the American market mentality turns US obstetric hospitals into high-tech factories, devoted to the "production" of the perfect baby.

1.3 The use of sophisticated technology during normal, uncomplicated childbirth also helps to explain how the management of birth by physicians has come to be seen as "heroic." But in fact, for the majority of women, pregnancy and childbirth are neither rare, nor pathological, events (van Teijlingen 2005; Davis-Floyd 1987). The medicalisation of childbirth obscures this fact. Most lay people know nothing about how ordinary women experience birth, nor do they understand the many and varied ways of organising birth safely. Rather, the taken-for-granted idea of childbirth as a frightening and dangerous event constitutes the dominant cultural representation of pregnancy and birth. A society's understanding of birth as risky affects the way maternity care is organised, how care is delivered, and what women come to expect of maternity services and, ultimately, birth itself. 
with birth care systems in three high-income countries in Northern Europe: the United Kingdom (UK), the Netherlands, and Finland. The social, political, and cultural organisation of birth varies greatly even between high-income countries with similar levels of medical technology (Benoit et al. 2005, De Vries 2005). The UK National Health Service (NHS) is a unique state-run health care system, and the UK way of organizing maternity care has been influential in many English-speaking ex-colonies. The Netherlands provides an example of maternity care that is reported to be both midwife and woman-friendly (DeVries 2005; van Teijlingen et al 2004), although satisfaction levels with maternity care can still be improved (Baston et al. 2008; Christiaens \& Bracke 2007). Finland is one of the Nordic countries that since the 1960s have had one of the lowest maternal and fetal mortality figures in the Europe Euro-Peristat 2008). In all of these countries, as in the US, there are high-quality hospitals and doctors with the most up-to-date technologies available. However, unlike the US, all three comparison countries (like all Northern European countries) have a well-developed midwifery profession that provides maternity care to the majority of women. In all three countries, midwives are the caregiver of choice for normal birth. Only when an instrumental delivery or a surgical birth is necessary will an obstetrical specialist be called upon, making it unusual for obstetricians to attend vaginal births.

1.5 The US differs from these three countries in birth outcomes and maternity care arrangements. Moreover, it is the only high-income country where until recently more than 15 percent of its population have no insured and guaranteed access to health care services; around 40 million Americans have no health insurance (De Vries 2004: 235). In 2006, nearly one in eight (12.1\%) of all children in the US lived in uninsured families (The Kaiser Foundation 2007: 4). Indeed, nearly one quarter of babies in the period 20002003 were born in poverty (Johnson \& Dye 2005). Therefore, instead of conducting a straightforward maternity care comparative study (Wrede et al. 2006; Benoit et al. 2005), we consider the unique characteristics of US maternity care to be a manifestation of its 'exceptionalism', i.e., of the ways in which the US is fundamentally different from other well-resourced countries (see e.g. Rodwin 1987; Nolte et al. 2005: 15). Our aim is not to offer the other countries as models for the US; rather, we use a comparative lens to provide a deeper understanding of the American ways of giving birth.

\section{American exceptionalism}

2.1 The idea of exceptionalism has been applied to the US in different sociological fields, but it was first put forth in a classic text by Sombart (1976) who noted that the US is the only high-income country that had no influential social democratic or communist party in the twentieth century. In a discussion on US political culture, Lipset (1996) argues that US exceptionalism arises from a dominant ideology of Americanism that depicts the US as a unique, open, and competitive society where citizens share values of individualism, anti-stateism, populism, and egalitarianism. The vital relevance of Americanism in US politics helps us understand how, while there is a universal support for equal social relations, these values do not provide a foothold for a shared responsibility for the social welfare of all.

2.2 American maternity care is not exceptional in its use of the hospital as the primary location for birth; rather it is the use of highly trained specialists (i.e., physicians) to attend nearly all births as the primary caregiver that sets the US apart (Table 1). In the Netherlands about 30\% of births occur at home with midwives attending the majority of those home births. Dutch midwives also attend a small proportion of hospital births, while obstetricians attend a high proportion of hospital deliveries. In Finland and the UK midwives attend the majority of births, and almost all occur in clinical settings. The reader is reminded that Table 1 shows data for England as proxy for UK. Since the NHS is run slightly differently in the four countries constituting the UK, this means overall data are difficult, if not impossible, to find. However, in the US certified-nurse midwives attended less than eight percent of all deliveries in any of the years in the period 1989-2005 (Declercq 2008).

Table 1: Proportion of births attended by doctors and midwives in Finland, the Netherlands, England and the US

\begin{tabular}{|l|c|c|}
\hline \multirow{2}{*}{ Country } & \multicolumn{2}{|c|}{ Birth attendant } \\
\cline { 2 - 3 } & $\begin{array}{c}\text { Physician } \\
\%\end{array}$ & $\begin{array}{c}\text { Midwife } \\
\%\end{array}$ \\
\hline Finland (2006) & $26^{*}$ & $74^{*}$ \\
\hline The Netherlands (2002) & 66 & 33 \\
\hline England (2006/07) & 35 & 62 \\
\hline United States of America (2005) & 92 & 7 \\
\hline
\end{tabular}


* The Finnish Birth Register does not collect data that specifies the professional qualification of the birth attendant. The figures calculated for this table are cautious estimates, so that the proportion of births attended by doctors is estimated to be all instrumental and surgical births, even though it is likely that some midwife-attended births are included in these births.

Sources: Finland: Finnish Birth Register 2007; the Netherlands: Anthony, S, AmelinkVerburg M.P., Jacobusse G.W. van der Pal-de Bruin K.M. (2005) 'De thuisbevalling in Nederland, 1995-2002', Rapportage over de jaren 2001-2002 van PRN/TNO, Bilthoven: Stichting Perinatale Registratie Nederland [ http://www.perinatreg.nl/uploads/153/99/Rapportage_Thuisbevalling_2001-2002.pdf]; England: NHS Maternity Statistics, England: 2006-07, The Information Centre http://www.ic.nhs.uk/statistics-and-data-collections/hospital-care/maternity/nhs-maternitystatistics-england:-2006-2007] ; US: Martin (2007); Declercq (2008).

We begin our analysis of US exceptionalism in childbirth with a description of the core features of the organisation of pregnancy and childbirth there.

\section{A. Core features of the organisation of childbirth in the US}

3.1 There are three important ways in which the organisation of birth care in the US differs from our three selected comparison countries. First, US health care is exceptional in its degree of social inequality: birth outcomes, along with other general measures of health and well-being, have a steep socio-economic and ethnic gradient. Second, birth control and especially abortion remain controversial issues that deeply divide the American public. Third, the high rate of litigation against US obstetricians reflects the market dynamic of US health care and the response of the legal system to that market.

\section{Social inequality is US maternity care}

3.2 Institutions and customs guide the birth of a human being and it is also a site where social equality has its most acute expressions. Disadvantaged groups in the US run much higher risks of birth-related health problems and even death compared to the middle and upper classes. The US has by far the highest income per capita of the four countries surveyed, yet it has the poorest health indictors. Table 2 shows some of the health indicators used to compare health care across and within different countries, as well as the Gross National Income per person in selected high-income countries. The infant mortality rate (IMR) represents the number of deaths of children less than one year of age occurring in a given year, expressed per 1,000 live births. Low birth weight is often an indication of poorer maternal health, and it is associated with a lower chance of survival of the baby. There is evidence for the association of the IMR and low birth weight, on the one hand, and the socio-economic status of individuals and income inequality in a given country, on the other (Spencer 2004). In other words, the babies of people at the lowest economic classes are more likely to have a low birth weight and to die in the first year of life.

3.3 Income inequality metrics are techniques used by economists to measure the distribution of income among members of a society. The GINI Index is a commonly used measure of income (in)equality: the higher the number, the greater the inequality.. It is thought that inequalities in the distribution of income in a society are a more important influence on health outcomes than total income and wealth (Wilkinson 1996). Thus we would expect to see that the less evenly distributed a country's wealth, the higher the IMR. This relationship is illustrated in Table 2.

Table 2: Selected comparative data health \& national development (2006)

\begin{tabular}{|l|c|c|c|c|c|}
\hline & $\begin{array}{c}\text { Gross national } \\
\text { income (US\$) } \\
\text { per capita p/a }\end{array}$ & $\begin{array}{c}\text { Income } \\
\text { inequality } \\
\text { Gini } \\
\text { index }\end{array}$ & $\begin{array}{c}\text { Infant mortality } \\
\text { rate, deaths per } \\
1,000 \text { live births }\end{array}$ & $\begin{array}{c}\text { Babies with } \\
\text { low birth } \\
\text { weight }(<2,500 \\
\text { grams) }\end{array}$ & $\begin{array}{c}\text { Life } \\
\text { expectancy } \\
\text { at birth }\end{array}$ \\
\hline US & 44,070 & 40.8 & 7 & $6 \% \mathbf{~}$ & $78 \mathrm{yrs}$ \\
\hline UK & 33,650 & 36.0 & 5 & $8 \% \mathbf{c}$ & $79 \mathrm{yrs}$ \\
\hline The Netherlands & 37.940 & 30.9 & 4 & $5-6 \%$ c & $80 \mathrm{yrs}$ \\
\hline Finland & 33,170 & 26.9 & 3 & $4 \% \mathbf{y r s}$ \\
\hline
\end{tabular}

data 2005; ' data 2000; ' data for period 2005/07; d data 1999 or 2000; " data 2001; 
accessed 4th August 2008; Martin et al. 2007: 33); CBS Statline (official Dutch Government statistics online: http://statline.cbs.nl/StatWeb/publication/?DM=SLNL\&PA=37302\&D1=1323\&D2=(I-11)-I\&VW=T), accessed 4th August 2008; United Nations Development Programme Report 2007 GINI date from UNDP webpages <http://hdr.undp.org/en/statistics/> accessed 6th August 2008.

3.4 American experts who are critical of current US maternity care arrangements have also pointed to the intersection of income inequality and other forms of vulnerability and maternal mortality. For example, Women's eNews (2001) reported:

- Women in urban areas and in several southern states that extends from North Carolina to New Mexico are far more likely to suffer a pregnancy-related death than women in other areas.

- Black women are four times more likely to die than white women from childbirth, pregnancy and their complications.

- Hispanic women in US are about 1.6 times as likely to die as white women, and those born outside the US fare much worse than those born here.

3.5 Of course such differences in access to care exist in all high-income countries, but generally, the proportion of women who do not access maternity services is very small. In the US, however, because of greater inequalities and a different funding system a relatively large proportion of women do not have proper access to maternity care., Black women are overrepresented in this group.

3.6 Other adverse pregnancy outcomes related to poor socio-economic status include the proportion of teenage conceptions and low-birth weight. Teenage pregnancy in high-income countries often leads to disadvantages in the young mother's life, as a consequence of lower educational attainment and subsequent access to the labour market (Botting et al. 1998), hence teen mothers are more likely to require public assistance (Gold et al. 2002:78). Teenage pregnancy and birth rates are high in the US, especially when compared to other high-income countries. Teenage pregnancy rates differ widely by race and ethnicity and appear to have been in decline in recent years (Santelli et al. 2007).

\section{Table 3. Rates of fertility, birth \& abortion per 1,000 women aged $15-$ 44, by ethnicity, USA}

\begin{tabular}{|l|c|c|c|}
\hline & All & White & Black \\
\hline Low birth weight (2005) & 64 & 53 & 119 \\
\hline Birth rate (2005) & 14 & 13 & 16 \\
\hline Abortion rate (2005) & 15 & 9 & 28 \\
\hline
\end{tabular}

Source: Birthweight \& birth (Martin et al. 2007: 33); abortion (Gamble et al. 2007)

3.7 Low-birth weight is associated with poverty, race, and ethnicity, lifestyle factors (especially smoking) as well as obstetric and biophysical characteristics (Goldenberg \& Culhane 2007). Black women are more than twice as likely to have low-birth weight babies than White women. Table 3 also indicates that there are differences between White and Black women of child-bearing age (15-44) becoming pregnant. White women are slightly less likely to become pregnant than their Black counterparts, but the latter is far more likely to have an abortion when they fall pregnant.

3.8 Social inequality in the US is also related to geographical diversity and the features of the current health care system. High-tech hospitals, complete with the latest (and most costly) medical technologies, exist only in cities, whereas in large rural parts of the country there is minimal maternity service provision. Many rural areas of the US operate without basic maternity services (Rhoades 2001: 128-9). There has been a scattered history of schemes providing midwifery care to remote, poor rural communities in the US. An example of one of these schemes is the Frontier Nursing Service in Kentucky, a state with many poor and remote communities in the Appalachian Mountains (see http://www.frontiernursing.org/). One problem with such schemes is that they may reinforce the message that midwifery care is for poor women and obstetric care for those who can afford it. Which it is not, as the growth midwifery services reimbursed by health insurance companies suggests (see below).

3.9 Apart from geographical disadvantage, many US women's experience barriers to quality maternity care because they do not have private health insurance and cannot afford to pay out of pocket for professional services. The dynamics of private markets and competition, together with the lack of national health insurance (or other systems of compulsory health insurance) frame the issue of access to maternity care in the US in a different way from how it is framed in European nations where access to health care is secured through such arrangements (Woodhandler \& Himmelstein 2007). 


\section{Abortion}

3.10 Conservative values in the US have a strong influence on policies related to birth control and abortion. The abortion issue has caused bitter struggles since the 1970s. While the pro-abortion position defends a woman's right to decide about her body, the so-called pro-life position argues that the idea of each individual's inviolable right to life is applicable to a foetus. In US politics adherence to such values has coincided with anti-statist positions that proclaim non-intervention in all areas of social life (Lockhart 2003). By contrast, despite the presence of similar irreconcilable ideological conflicts on abortion in the society, the general acceptance of governmental involvement has made political compromises on birth control and abortion possible in the three comparison countries. While abortion legislation differs in these three countries, all make abortion easily available but treat it as a last resort solution.

3.11 In the US birth control and abortion are still hotly debated in society and politics, as it was in the 2008 presidential election (e.g. Kincaid 2008; NARAL Pro-Choice America 2008). The strong influence of conservatism in US politics has made it difficult to achieve social consensus over the availability of abortion services. Moreover, Kahane (2000) argued that anti-abortion activities have made abortion service scarcer in the US. Similar continuous struggles are rare in the Netherlands, Finland and the UK.

3.12 The high rate of teenage pregnancies in the US is related to a moral conservatism that limits the availability of information about sexuality and reproduction, making it difficult for teenagers to access nonjudgemental family planning, contraception, and abortion services. For example, the US campaigning organisation, Advocates for Youth, compared three European countries (the Netherlands, France and Germany) with the US in terms of sexual health outcomes. It suggested that the US has higher teen pregnancy rates and teen abortion rates because it lacks: "1) societal openness and comfort in dealing with sexuality, including teen sexuality; and 2) pragmatic government policies" (Alford \& Hauser 2008). On the other hand, teenage motherhood is associated with income levels, income inequality and social capital (Gold et al. 2002).

\section{Litigation}

3.13 Lacking universal health insurance, many parents in the US are on their own when something goes wrong during childbirth. Whereas in the Netherlands, the UK and Finland there would be state-funded or state-supported health care to deal with seriously ill babies and/or mothers, in the US it is rational to resort to suing the hospital, the doctor, the ambulance company, or the midwife. The need to sue to make provision for the future means that lawyers have started specialising in medical litigation cases, creating a demand for litigation services. This in turn means insurance premiums go up, as insurance companies lose money every time doctors are being sued successfully or settle out of court. As one of the first California midwives to be sued explained: "The more professionals are insured for, the higher the malpractice awards. Then the hospitals require their doctors to carry even more insurance, all that does is encourage more lawsuits with bigger settlements. It's a nasty spiral with no end in sight" (quoted in Vincent 2002: 306). In fact, even twenty years ago US obstetricians could expect to be taken to court an average of eight times during their careers for "less than optimal" outcomes (Schifrin et al. 1985). Not surprisingly, practitioners fear those few times when something does go wrong with the mother or baby, a fear that is compounded by the "statute of limitations" in the US that allows cases to be litigated any time during the twenty-one years following the birth of the baby (Cartwright \& Thomas 2001: 222). MacLennan et al. (2005) report that 76\% of obstetricians in the US have faced litigation. For US practitioners, then, the issue of safety in childbirth is enmeshed in a legal system looking to blame someone for "bad outcomes" that inevitably occur. Fear of lawsuits (even if unfounded), impacts upon practitioners' use of technology and diagnostic testing as protective devices (Annandale 1996: 434) what is refered to as 'protective medicine' (Horton 2005). Moreover, the threat of litigation is one of the major reasons for US obstetricians leave obstetrics (MacLennan et al. 2005) and move to the field of gynaecology, which attracts less litigation.

3.14 The organisation of maternity care anywhere is a product of ideas about health, illness, and the proper use of medicine and medical technology. Here, too, the US is exceptional, with its unique combination of expensive private health care, largely funded through commercial insurance companies; its means-tested programmes for the very poor; its structural inequality in access to health care dependent upon class, race, ethnicity, geographical location; and its poor global health ranking. The US 'moralistic' society, with a high level of litigation and low level of maternity care attended by midwives, sets it apart from other high-income countries, including in regard to how childbirth itself is organised.

\section{B. Medicalisation and hospitalization of birth}

4.1 Compared to other countries in Europe, the US made the earliest and most rapid shift to hospitalization of childbirth. The biggest changes occurred in the late 1930s; by 1954 only six percent of US births took place outside of hospitals. The figure for Finland at the time was 25\%; the UK, 36\%; and in the Netherlands, over three-quarters of babies were born at home in the middle of the $20^{\text {th }}$ century (Declercq et al. 2001: 8). Hospitalization of birth in the US was related to developments in hospital medicine, as well as in medical care in general. In parallel with public policy that invested in hospital medicine as a site of scientific excellence, the US also turned to individual or workplace health insurance (in keeping with notions 
of individualism enshrined at a public policy level), supplemented by the state-funded Medicaid programme, which reimburses costs for services delivered to poor (McKinlay \& Marceau 2008).

4.2 The public, subsidized by insurers, became more accustomed to using the local hospital for all medical services, and with some of the costs of a hospital birth now covered, the incentive to give birth in a hospital grew rapidly (Declercq et al. 2001: 11). New technologies for pain management in birth also played an important role in creating consumer demand for hospital birth. Since pain relief generally had to be administered in a hospital - unlike in the UK where midwives were trained to administer some forms of inhalational analgesia in out-of-hospital settings - women who sought it were no longer able to give birth at home.

4.3 As upper middle-class women in the US began to choose hospital birth early in the twentieth century, hospitals soon came to be seen as the place for "proper women" to have their babies. Immigrant mothers recognized hospital birth as a true American practice, a mark of assimilation into a new society (Borst 1995). A midwife who catered to the poor in New York around 1900, when only the poor and some of the immigrant groups still used the services of the midwife described how immigrants came to adopt the American ways of giving birth: "Those who had risen in the scale of material Americanism lost their native diffidence with many other traits. Like the American women they, too, would be confined only by doctors" (Goldman 1971: 185).

4.4 During the first decades of the twentieth century, midwifery in the US rapidly became a low status occupation. By way of contrast, in the UK, Finland, and the Netherlands the midwifery elite were reinventing the profession as an occupation for aspiring middle-class young women as they moved into the workplace (Heagerty 1997, Wrede 2001, De Vries 2005, Sandall 1996). Wiedenbach (1960:256) pointed out the negative connotation acquired by the term midwife in the US, although in the same period (first half twentieth century) there is some evidence of decline in the status of midwifery the UK (Heagerty 1997). In the US midwives were regarded as well-intentioned, but uneducated, old women. However, when mortality statistics in the US were analysed, midwives did better than expected, considering that they worked with the poorer, worse nourished, inadequately housed population (Devitt 1979). Even though midwives had bad press, some US doctors admitted that a "poorly trained physician does far more harm than the midwife ..." (Lobenstine 1911:877). It is important to recognise that in the early twentieth century a battle was waged in the US between birth care professionals (Leavitt 1987), resulting in the near extinction of midwifery. Devitt (1979) pointed out that many doctors argued their case without being able to back up their arguments with facts.

4.5 As noted above, the virtual elimination of midwifery in the US also contributed to the demise of home births. The presence of midwives, many of them immigrants, significantly complicated efforts to promote the obstetric specialty. A senior obstetrician of the day noted: "Do you wonder that a young man will not adopt this field as his special work? If a delivery requires so little brains and skill that a midwife can conduct it, there is no place for him" (Litoff 1978: 67). While the discussion about the future of the midwife was in progress, American women were turning away from midwives.

4.6 If elite women were so influential in shaping US maternity care, why didn't they help their "sisters," the midwives, who were under attack by doctors? The answer is simple - they didn't consider them sisters-inarms. In the early twentieth century there were profound social class, ethnic, and racial differences between the largely immigrant midwives and those women who desired pain relief in childbirth. Pain relief advocates, supportive of the general inclination toward science and technology, became allied with physicians -- what was then a predominantly male professional elite -- who were making birth more 'scientific' (Starr 1982). Equally important is that midwives lacked the class privilege to act as an effective interest group and, divided by social class ethnic differences and with no sense of profession, they failed to work together to protect their own interests (Declercq \& Lacroix 1985). A sociologist in the early twentieth century commented that midwives "are little used at the present time by women of native parentage" (Abbott 1915: 685). It is clear from the text that 'native parentage' does not refer to the present day 'Native Americans', but to second (or third) generation women in the US who were of European descent (as supposed to recently arrived European immigrants. Moreover, midwives also were not supported in their professionalisation process by other professionals such as nurses and doctors (Ettinger 2006), although this was partly true for the European countries the latter has support from state in terms of licensing and funding.

4.7 Medicalisation of childbirth would have been impossible without the redefinition of birth from a natural event to one of "imposing pathologic dignity" (Litoff 1978, p. 67; van Teijlingen 2005). The popular press succeeded in portraying birth as unnatural and dangerous for mother and baby. Mass media portrayals continue to be typically traumatic (Birth Issues Winter 2004-2005). Childbirth appears to have dramatic potential for entertainment, whilst normal, uneventful births are less interesting for the media. To be sure, it would be simplistic to claim that most of the knowledge of birth that residents of US have comes from the media. Furthermore, this kind of media imagery is not unique to the US. Analysis of media portrayals of birth in the UK shows that having a child is unrealistically risky for a television character (Clement 1998). Nevertheless, it is evident that the framing of birth as risky and traumatic by media in the US is influential in shaping how people think and act. 
4.8 The medicalisation of childbirth became one of the core targets of counter-culture criticism of the 'health industry' produced by social movements in the 1970s. These movements were embedded in the rise of the larger social movements of the era, i.e. the women's movement, civil rights movement, and consumer movement. In this age of social activism, it was lack of choice rather than differential access to maternity care that became the core issue for birth activists. Like the early pain relief movement, home birth and other alternative birth movements were fundamentally middle-class movements for which poor women's access to care was not the primary impetus. This criticism and the activities undertaken by such movements led to the return of the midwife in many different guises (Davis 2007).

\section{Alternatives to medicalized birth care}

5.1 At present, there are several different types of midwives in the US, distinguished by their training and worldview: here we discuss just two core types of midwives, certified nurse-midwives and midwives who are not nurses. The growth of certified nurse-midwifery resulted in part from health insurers who saw them as a means of containing costs and accommodating demands for choice. In some areas of the US certified nurse-midwives are emerging as a key part in the provision of maternity care. For example, in Kalamazoo, Michigan, health insurers use a fixed fee to reimburse the hospital for maternity care. Hospitals there have started to employ nurse-midwives to provide delivery care on the labour wards because it is less expensive; this also happened elsewhere, including in New York City (De Vries 2005, 240). For example, "Health insurers licensed in New York must provide maternity care coverage, which includes prenatal, delivery and postnatal services, through a licensed midwife" (State of New York Insurance Department 2000). Integration into insurance arrangements makes nurse-midwifery an officially recognized form of health care that has been accommodated, if not co-opted, by medicine. This dominant system in the US, based on private health care providers and hospitals paid for by commercial health insurance companies, is slowly integrating nurse-midwifery, not for ideological reasons or health care improvement but largely for economic reasons.

5.2 In contrast to nurse-midwives, midwives who are not nurses often have "learned about birth by attending the births of friends, reading books, and apprenticing with other midwives, nurses, or, on some occasion, physicians" (Benoit et al. 2001: 143). The ideology behind this type of midwifery challenges the medical understanding of birth. The Farm in Tennessee is an example of apprentice-trained midwives growing into an organisation known the world over, in part because of active promotion by its founder Ina May Gaskin (2002). Through developments like the Farm, non-nurse midwifery has become established as part of the formal system in the US. Non-nurse midwives in the US now have their own professional organisation, MANA (Midwives' Alliance of North America), providing certification for non-nurse midwives and monitoring home birth outcomes for its members. According to recent reports, the birth outcomes for these midwives are as good as other forms of US birth care (Johnson \& Daviss 2005; Jackson et al. 2003). This type of midwifery has not, however, become widespread. The use of such services requires both cultural and economic resources. Cultural resources are needed to make it possible to design the birth to one's own choice. As services are often not covered by insurance, women need to have funds to pay for their care, limiting access to this type of maternity care to women who can afford to pay for it, or the rare cases where a woman is covered by a health insurance company willing to pay for midwifery services in the home. By contrast, in the UK, the Netherlands, and Finland midwives, maternity care advocates, and services users have tried to improve the quality of existing maternity care offered by the state, rather than trying to establish a new provision as was the case in parts of the US.

5.3 The desires of birthing women, the choices and strategies of maternity care professionals, and the overall organisation of maternity care and health care systems are driven by cultural ideas about the proper relationship between individuals and society. This is clearly seen in the values that support the American way of birth.

\section{Born in the USA: Individuality versus solidarity}

6.1 The high level of medicalisation of birth in the US (Clarke et al, 2003; Conrad and Leiter, 2004) seems contrary to another commonly held value - the admiration of simple and rational approaches to problems and policies (De Vries et al. 2004: 229). Seen in this light, the US way of birth is at odds with its own values: there are billions of dollars to be saved by reducing the many technological interventions in birth interventions that seem completely unnecessary when looked at in comparison to other countries. But rational policy regarding cost containment is overruled by the US's extreme emphasis on individuality, noted long ago in the de Tocqueville's famous book Democracy in America (published in 1830). De Tocqueville (1969: 508) explains that equality between people in US society 'created' the spirit of individuality, thus: "A society of equals, in which individuals are expected to (and largely do) support themselves, turns every man's thoughts to himself (sic). This encourages a withdrawal from society at large. "

6.2 How does this value relate to birth? First, Americans dislike the idea of government regulation of the organisation of maternity care. Most women in the US would be uncomfortable with the Dutch, Finnish, and UK policies that disallow access to specialist obstetric care when a pregnancy is not showing any problems. These countries used national evidence-based policies and guidelines to argue that healthy pregnant women do not need expensive obstetric care but rather social support and health monitoring by a well-trained midwife. Secondly, as both de Tocqueville (1969) and Riesman (1952) pointed out, extreme 
individualism allows for manipulation of people. Cut free from traditions, left on their own, Americans are susceptible to advertising and medical authority. In Riesman's terms, Americans are "other-directed," they look to each other when deciding what is the best thing to do. In the absence of a countervailing tradition, women must rely on the expert advice of physicians, advice that is clouded by professional interests and socialisation.

6.3 The link between cultural ideas and health systems is mediated by the political structure of a country. One important difference between the US and the countries of Europe is a higher level of solidarity in the latter. But it can also be argued that understandings of solidarity differ in the US and Europe. American attitudes about solidarity with regard to access to health care were formed in the nineteenth century as large numbers of immigrants settled in the country's urban areas. By way of contrast, in the UK, the Netherlands, and Finland, powerful interest groups (including socialists) viewed poverty as an outcome of the economic system (Rodwin 1987). The attitude of solidarity allows the Dutch, the Finns, and the Brits to see their own health care in the light of the larger system ("if I demand specialist care for my normal birth it will drive the cost of health care up and reduce access for others") and promotes cooperation between different caregivers in the health care (and maternity care) system. Such attitudes are shared by a substantial minority, but not the majority, of citizens (De Vries et al. 2004: 230).

6.4 The health policies of Finland, the UK, and the Netherlands - all of which include a guaranteed basic package of benefits, controls on the price/cost of services, and limited access to certain services - give evidence of a cultural notion of "solidarity" where members of society care for each other. Health policy in the US is more individualistic and market-driven. The predominant inclination in the US among those with the greatest power is to regard poverty as an individual problem. Furthermore, there is a general aversion among Americans to universal entitlements (Rodwin 1987).

\section{Conclusion}

7.1 The concept of exceptionalism is a useful way to examine the social organisation of maternity care in the US. We have highlighted the essential ways that the US differs from the Northern European countries of the UK, Finland, and the Netherlands, all of which are high-income countries with well-funded public hospitals and highly-trained primary health care workers. The dominant cultural values held by the US populace have had a decisive influence on the way care during pregnancy and birth is organised. There is a noticeable lack of popular support for a publicly-funded health care system, which is central to the notion of exceptionalism in the US system. Yet at the same time these general cultural values interact with each other and the socio-economic environment. Thus the kind and quality of maternity care available to certain groups of US women (and not others) is influenced by historical developments, the portrayal of childbirth in the mass media, the way in which both the health care system and the accompanying health insurance system is organised, the risk of litigation experienced by obstetricians, and by inter-professional conflict rather than collaboration.

7.2 Studying such wide-ranging concepts comparatively helps us understand why greater use of birth technology is equated so strongly with 'safety' in the US. This approach also provides insight into the question of why midwives are slowly making their way back into the US maternity care system (Ettinger, 2006).

7.3 The US has been recognised for its 'exceptionalism' in different sub-disciplines of sociology. Our sociological analysis of the organisation of maternity care there fits this general pattern. Hence rather than attempting to squeeze the US maternity care system into a straight-forward cross-national comparison with other high-income countries, we must reflect on the limitations of any such comparative studies incorporating the US maternity care system. Furthermore, the consideration of US exceptionalism directs our attention to the complex and dynamic multi-dimensional nature of any political culture, forcing us to closely consider how we compare, as well as what and why we compare.

\section{References}

ABBOTT, G. (1915)' The midwife in Chicago', American Journal of Sociology 20: 684-699.

ALFORD, S. and HAUSER, D. (2008) Adolescent sexual health in Europa and the U.S. -Why the difference? Washington D.C.: Advocates for Youth <http://www.advocatesforyouth.org/PUBLICATIONS/factsheet/fsest.pdf> Retrieved 30/12/2008.

ANNANDALE, E. (1996) 'Working on the front line: risk culture and nursing in the new NHS', Sociological Review, 44: 416-451.

BASTON, H., RIJNDERS, M., GREEN, J., BUITENDIJK, S. (2008) 'Looking back on birth three years later: Factors associated with a negative appraisal in England and in the Netherlands'. Journal of Reproductive \& Infant Psychology, 26: 323-339.

BENOIT, C., DAVIS-FLOYD, R., TEIJLINGEN VAN, E., SANDALL, J. and MILLER, J. (2001) Designing midwives: A comparison of educational models, In: DE VRIES, R, BENOIT, C., VAN TEIJLINGEN, E. and 
WREDE, S. (2001) Birth by Design: Pregnancy, Maternity Care and Midwifery in North America \& Europe . New York: Routledge, pp.139-165.

BENOIT, C. WREDE, S. BOURGEAULT, I. SANDALL, J. DE VRIES, R. and VAN TEIJLINGEN, E.R. (2005). 'Understanding the social organisation of maternity care systems: Midwifery as a touchstone', Sociology of Health and IIIness , 27:722-737.

BIRTH ISSUES (2004-2005) A best approach to birthing. Birth Issues, winter 2004-2005, volume XIX, number 2. ,http://www.asac.ab.ca/BI_winter0405/toc.html. Retrieved 04/03/2008.

BORST, C. (1995) Catching babies: the professionalization of childbirth, 1870-1920 . Cambridge, MA: Harvard University Press.

BOTTING, B., ROSATO, M. and WOOD, R. (1998) Teenage mothers and the health of their children. ONS Population Trends, 93: 19-28.

CARTWRIGHT, E. and THOMAS, J. (2001) 'Constructing Risk: Maternity care, law, malpractice', in R. DeVries, C. Benoit, E.R. van Teijlingen and S. Wrede (editors) Birth by Design: Pregnancy, maternity care, and midwifery in North America and Europe, New York: Routledge.

CHRISTIAENS, W. and BRACKE, P. (2007) 'Place of birth and satisfaction with childbirth in Belgium and the Netherlands'. Midwifery. May 16.

CLEMENT, S. (1998) 'Television gives a distorted picture of birth as well as death', British Medical Journal, 317: 284

CLARKE, A.E., SHIM, J.K., MAMO, L., FOSKET, J.R., and FISHMAN, J.R. (2003) 'Biomedicalization: technoscientific transformations of health, illness, and U.S. biomedicine', American Sociological Review 68: 161-194.

DAVIS, K. (2007) The making of our bodies, ourselves: how feminism travels across borders, London, Duke University Press

DAVIS-FLOYD, R.E. (1987) 'The technological model of birth', Journal of American Folklore, 100: 479-95.

DECLERCQ, E.R, (2008) 'Births attended by certified-nurse-midwives in the United States in 2005', Journal of Midwifery \& Women's Health 54: 95-96.

DECLERCQ, E.R, DEVRIES, R, VIISAINEN, K, SALVESON, H. and WREDE, S. (2001) 'Where to Give Birth? Politics and the Place of Birth'. In Birth by Design. DEVRIES R, BENIOT C, VAN TEIJLINGEN E, WREDE S, (eds.), New York: Routledge, pp. 7-27.

DECLERCQ, E. and LACROIX, R. (1985) 'The immigrant midwives of Lawrence: the conflict between law and culture in early twentieth-century Massachusetts'. Bulletin of the History of Medicine 59(2):232-246.

DEVITT, N. (1979) 'The Statistical Case for Elimination of the Midwife: Fact versus Prejudice, 1890-1935 (Part 1)', Women \& Health, 4: 81-96

DE VRIES, R. (2005) A Pleasing Birth. Midwives and Maternity Care in the Netherlands . Philadelphia: Temple University Press.

DE VRIES, R., WREDE, S., VAN TEIJLINGEN, E., BENOIT, C. and DECLERCQ, E. (2004) Making maternity care. The consequences of culture for health care systems. In: Comparing Cultures. Dimensions of Culture in a Comparative Perspective. VINKEN, H. SOETERS, J. and ESTER, P. (eds.) Leiden, the Netherlands: Brill.

DE TOCQUEVILLE, A., (1969) Democracy in America. MAYER, J. P. (ed.), (translated by George Lawrence). New York: Anchor.

DUTTON, P.V. (2007) Differential Diagnoses: A Comparative History of Health Care Problems and Solutions in the United States and France. New York: Cornell University Press.

ETTINGER, L.E. (2006) Nurse-Midwifery: The Birth of a New American Profession Columbus, USA: Ohio State University Press.

EURO-PERISTAT (2008) European Perinatal Health Report Better statistics for better health for pregnant women and their babies, <http://www.europeristat.com/publications/european-perinatal-healthreport.shtml> Accessed 3/01/09

GAMBLE, S.B., STRAUSS, L.T.PARKER, W.Y., COOK, D.A., ZANE, S.B., HAMDAN, S (2007) 'Abortion Surveillance: United States, 2005', MMRW Surveillance Summaries 57 (SS13): 1-32.

GASKIN, I.M. (2002) Spiritual Midwifery (4th edn), Summertown, TN: Book Pub. Co. 
GOLD, R., KENNEDY, B., CONNELL, F. and KAWACHI, I. (2002) 'Teen births, income inequality, and social capital: developing an understanding of the causal pathway', Health \& Place 8: 77-83.

GOLDENBERG, R.L. and CULHANE, J.F. (2007) 'Low birth weight in the United States', American Journal of Clinical Nutrition 85 (Suppl.): 584S-590S.

GOLDMAN, E. (1971), Living my Life (reprint of 1931 edition), New York: Dover Publ.

HEAGERTY, B.V. (1997) Willing handmaidens of science? The struggle over the new midwife in early twentieth-century England, in Reflections on Midwifery. KIRKHAM M.J. and PERKINS E.R.(eds.), London, Bailliere Tindall.

HORTON R. (2005) 'Medicine: the prosperity of virtue', Lancet 367: 366.

JACKSON, D.J., LANG, J.M., SWARTZ, W.H., GANIATS, T.G., FULLERTON, J., ECKER, J. and NGUYEN, U. (2003) 'Outcomes, safety, and resource utilization in a collaborative care birth center program compared with traditional physician-based perinatal care', American Journal of Public Health, 93: 999-1006.

JOHNSON, K.C. and DAVISS, B-A. (2005) 'Outcomes of planned home births with certified professional midwives: large prospective study in North America', British Medical Journal 330: 1416.

JOHNSON, T. and DYE, J. (2005) 'Indicators of Marriage and Fertility in the United States from the American Community Survey: 2000 to 2003', US Census Bureau, Population Division, Washington DC. <http://www.census.gov/population/www/socdemo/fertility/mar-fert-slides.html> Retrieved 04/08/2008.

KAHANE, L.H. (2000) 'Anti-abortion activities and the market for abortion services', The American Journal Economics \& Sociology, July <http://findarticles.com/p/articles/mi_m0254/is_3_59/ai_63548066? tag=artBody; col1> Retrieved 28/12/2008

KINCAID, C. (2008) 'Abortion and America's future' Accuracy in Media (21 Jan 2008)

<http://www.aim.org/special-report/abortion-and-americas-future/> Retrieved 28/12/2008

LEAVITT, J.W. (1983) "'Science" enters the Birthing Room: Obstetrics in America since the Eighteenth Century', Journal of American History , 70: 281-304

LEAVITT, J.W. (1987) 'The growth of medical authority: technology and morals in turn-of-the-century obstetrics', Medical Anthropology Quarterly. (new series), 1:230-55

LIPSET, S.M. (1996) American Exceptionalism: A Double-Edged Sword. New York: W.W. Norton \& Company Inc.

LITOFF, J.B. (1978) American Midwives: 1860 to the Present, Westport, Conn.: Greenwood Press.

LOCKHART, C. (2003) The Roots of American Exceptionalism: Institutions, Culture and Policies. New York: Palgrave Macmillan.

LOBENSTINE, R.W. (1911) 'The influence of the midwife upon infant and maternal morbidity and mortality', American Journal of Obstetrics and Diseases of Women \& Children , 63: 876-80

MACLENNAN, A.H., NELSON, K.B., HANKINS, G., and SPEER, M. (2005) 'Who will deliver our grandchildren? Implications of Cerebral Palsy litigation', Journal of the American Medical Association, 294 : 1688-90.

MARTIN, J.A., HAMILTON, B.E., SUTTON, P.D., VENTURA, S.J., MENACKER, F, KIRMEYER, S., and MUNSON, M.L. (2007) Births: Final data for 2005, National Vital Statistics Reports; Vol 56 (6). [ http://www.cdc.gov/nchs/data/nvsr/nvsr56/nvsr56_06.pdf]

M $\mathrm{C}_{\mathrm{KINLAY}}$, J. and MARCEAU, L. (2008) 'When there is no doctor: Reasons for the disappereance of primary care physicians in the US during the early $21^{\text {st }}$ century', Social Science \& Medicine $67: 1481$ 1491.

NARAL PRO-CHOICE AMERICA (2008) 'Sen. Barack Obama's record on choice', <http://www. prochoiceamricaorg/elections/statements/obama.html> Retrieved 28/12/2008

NELSON, M.K. and POPENOE, R. (2001) 'Looking within: race, class, and birth.' Birth by Design. DEVRIES R, BENIOT C, VAN TEIJLINGEN E, WREDE S, (eds.), New York: Routledge, 87-111.

NOLTE, E., MCKEE, M, and WAIT, S. (2005) Describing and evaluating health system In: Handbook of Health Research methods: Investigation, measurement and analysis, BOWLING A and EBRAHIM S (eds.), Maidenhead: Open University Press, pp.12-43. 
PERKINS, B.B. (2004) The Medical Delivery Business. Health Reform, Childbirth, and the Economic Order. New Brunswick: Rutgers University Press.

RIESMAN D and GLAZER N. (1952) Faces in the crowd. New Haven, CT: Yale University Press.

RHOADES E.R. (2001) American Indian Alaska Native Health Services as a System of Rural Care. In: LOUE, S. and QUILL, B.E. (eds.), Handbook of Rural Health. New York: Kluwer/Plenum Publishers, pp. 119-33.

RODWIN, V.G. (1987) 'American exceptionalism in the health sector: the advantages of "backwardness in learning from abroad', Medical Care Review, 44: 119-153

SAKALA, C. CORRY, M.P. (2008) Evidence based maternity care; what it is and what it can achieve, Childbirth Connection, Reforming States Group, Milbank Memorial Fund.

SANDALL J. (1996) Continuity of midwifery care in Britain: A new professional project, Gender, Work and Organisation 3 (4): 215-26.

SANTELLI, J.S., LINDBERG, L.D., FINER, L.B. and SINGH, S. (2007) Explaining recent declines in adolescent pregnancy in the United States: the contributions of abstinence and improved contraceptive use. American Journal of Public Health, 97: 150-156.

SCHIFRIN B.S., WEISSMAN, H., WILEY, J. (1985) 'Electronic fetal monitoring and obstetrical malpractice', Law, Medicine \& Health Care 13:100-105.

SOMBART, W. (1976) Why is there no socialism in the United States? (translated by P.M. Hocking and C.T. Husbands), Basingstoke: Macmillan

SPENCER, N. (2004) 'The effect of income inequality and macro-level social policy on infant mortality and low birthweight in developed countries - a preliminary systematic review', Child Care, Health \& Development, 30: 699-709.

STARR, P, (1982) The Social Transformation of American Medicine. New York: Basic Books.

STATE OF NEW YORK INSURANCE DEPARTMENT (2000) 'Re: Health Insurance Coverage for Midwifery Services', New York: State of New York Insurance Dept.

<http://www.ins.state.ny.us/ogco2001/rg108131.htm>. Retrieved 04/08/2008.

THE KAISER FOUNDATION (2007) Health Insurance Coverage in America: 2006 Data Update, Menlo Park, California, USA: The Henry J. Kaiser Family Foundation.

<http://www.kff.org/uninsured/upload/2006_DATA\%20_UPDATE.pdf> Retrieved 04/08/2008.

UNITED NATIONS (2004) United Nations Development Programme Report 2004, United Nations p50-53)

VAN TEIJLINGEN, E., LOWIS, G., MCCAFFERY, P. and PORTER M. (Eds.), (2004). Midwifery and the Medicalization of Childbirth: Comparative Perspectives. Hauppauge NY: Nova Science Publishers.

VAN TEIJLINGEN, E. (2005) 'A critical analysis of the medical model as used in the study of pregnancy and childbirth', Sociological Research Online, 10 (2) Web address:

<http://www.socresonline.org.uk/10/2/teijlingen.html>

VINCENT, P. (2002) Baby Catcher: Chronicles of a modern midwife, New York: Scribner.

WIEDENBACH, E. (1960) 'Nurse-midwifery: purpose, practice and opportunity', Nursing Outlook, 8: 256259

WILKINSON, R.G. (1996). Unhealthy Societies: the afflictions of inequality. London: Routledge.

WOMEN'S ENEWS 11/01/01 Woman's Craft Depicts Needless Deaths of Mothers Rebecca Webber. <http://www.womensenews.org/article.cfm/dyn/aid/705>

WOODHANDLER, S. and HIMMELSTEIN, D.U. (2007) Competition in a publicly funded health care system, British Medical Journal 335 : 1126-1129.

WREDE, S. (2001) Decentering Care for Mothers. The Politics of Midwifery and the Design of Finnish Maternity Services. Turku, Finland: Åbo Akademi University Press.

WREDE, S., BENOIT, C. BOURGEAULT, I. VAN TEIJLINGEN, E. SANDALL, J. and DE VRIES, R. (2006). Decentered Comparative Research: Context Sensitive Analysis of Maternal Healthcare. Social Science and Medicine 63, 2986-2997. 